\title{
Interception and Characterization of Trichoderma koningiopsis Reported in Imported Wooden Logs to India
}

\author{
J. Raju ${ }^{1 *}$, M. Gokulraam ${ }^{1}$, S. Priti ${ }^{2}$, M. Krishna Reddy ${ }^{2}$ and M. S. Akhtar ${ }^{3}$ \\ ${ }^{1}$ Ministry of Agriculture and Farmers Welfare, Government of India, Plant Quarantine \\ Station, Mangalore, Karnataka, India \\ ${ }^{2}$ ICAR-Indian Institute of Horticultural Research, Division of Plant Pathology, \\ Hessaraghatta Lake PO, Bangalore, Karnataka, India \\ ${ }^{3}$ Deputy Director, Ministry of Agriculture and Farmers Welfare, Government of India, \\ Regional Plant Quarantine Station, Bangalore, Karnatka, India \\ *Corresponding author
}

\section{A B S T R A C T}

\section{Keywords}

Trichoderma koningiopsis, Plant Quarantine,

Molecular

characterization,

Imported wooden

logs, Discolouration

Article Info

Accepted:

10 January 2021

Available Online:

10 February 2021
Throughout the import inspection of wooden logs from Ghana and Panama a profuse amount of white cottony mycelium was observed numerous times in consignments. The fungal pathogen was identified as Trichoderma koningiopsis by morphological and molecular characterization. Though it's not a tree pathogen but has been reported to cause wood discolouration and disfiguration. Inspection of imported wooden logs encumbers major challenge for detection of pathogen in timber logs owing to lack of available information for species identification of intercepted pathogens. The article aims at providing valuable information towards taxonomic identification.

\section{Introduction}

International trade and travel have opened new frontiers for countries to increase economy and as well to enjoy the products and services of those from distant lands. It has also led to increased risk of introduction of new pest and pathogens (Raju et al., 2019). India has emerged as a major importer of tropical woods/timber in recent years (Rao and Remadevi, 2006). These woods are usually dry or in semidry condition for uses ranging from structural material for construction to beautiful custom-made furniture. These woods may be poorly packed, exposed and under treated providing amply opportunity for bio -invasion. As of now very few reports are available on the 
entry of plant pathogens in imported wooden logs in India (http://164.100.163.200/ PQISMain/Default.aspx\#). This is because the plant pathogen encountered during import of wooden logs draws minimum attention since: they may not be recognized as harmful in their native ranges; timber not being an essential commodity, there are very few pathogens reported infecting the wooden logs. Recently, during the import of teak wooden $\log$ s, it was observed that most of the consignments were fully covered with white mycelial growth covering the entire wooden logs resembling that of pure cotton. It may be due to improper treatment at the point of loading or due to congenial humid conditions prevailing in the container during the transit. There is no proper information whether this mycelial growth will affect the quality of wooden $\operatorname{logs}$ or whether they are tree pathogens. Though some species of Trichoderma i.e. Trichoderma koningiopsis, T. dorotheae and T. gamsii were reported to cause wood discoloration in South Korea (Huh et al., 2011).

Samples of decayed wood collected from forest of Poland reported many Trichoderma species along with Trichoderma koningiopsis (Błaszczyk et al., 2015). Probably, the little attention focused on wood-colonizing Trichoderma species can be explained by the fact that they cause little or no structural damage except for the disfigurement of the wood surface. Nevertheless, the economic damage is high as discoloured wood losses in value (Huh et al., 2011). In this context an attempt was made to identify the fungal pathogen from imported woods/timbers.

\section{Materials and Methods}

Inspection of imported wooden logs were done as per the Plant Quarantine Order (Regulation of Import into India) 2003 and Standard Operating Procedures for Import inspection at Plant Quarantine Station, Mangalore. Teak wooden logs (Tectona grandis) were imported from Panama and Ghana countries. During the inspection whitish mycelia mat type growth of fungus was observed on the bark as well as core part of wooden logs. Beneath this superficial growth of mycelium, patches of light to dark brownish discoloration of wood was observed. Hence the infected parts of wooden $\operatorname{logs}$ as well as mycelial growth were collected for lab analysis.

The Intercepted fungal pathogen was collected in vials containing sterile distilled water, along with chips of wood logs covered with fungal growth and was sent to ICARIndian Institute of Horticultural Research, Division of Plant Pathology, Bengaluru for Morphological and molecular characterization.

The samples received from Plant Quarantine Station; Mangalore were subjected to isolation. The samples were subjected to standard surface sterilization procedures: small cut pieces were washed repeatedly in sterilized distilled water and one time in 4 percent sodium hypochlorite solution for 1 min, followed by 3 to 4 wash in sterilized distilled water.

The wood pieces were transferred to autoclaved petriplates containing Potato dextrose agar (PDA) and incubated at room temperature for further observations. After 10 days of incubation the mycelial growth was subcultured and utilized for morphological and cultural characterisation.

To standardise growth media, the pathogen was sub-cultured on different media i.e. Potato Dextrose Agar, Carrot Dextrose Agar, Potato Carrot Agar, Richards Synthetic Agar, Rye Dextrose Agar and Corn Meal Agar. 


\section{Morphological identification}

The infected wood sample and mycelium were examined under the light microscope for morphological studies. The mycelia of cultured fungus was mounted on glass slide and observed under microscope at different magnification. Cultural characters on different media were recorded.

\section{Fungal genomic DNA purification}

The cultured fungus was inoculated in Potato Dextrose Broth at room temperture for 10 days. The fungal mycelium was collected by filtration through Whatman No.1 filter paper and dried. Total genomic DNA isolation was carried out by following CTAB method (Doyle and Doyle 1990). The isolated DNA was dried, re suspended in $50 \mathrm{ml}$ of TE buffer (10 mM Tris-HCl, pH 7.5; 1 mM EDTA, $\mathrm{pH}$ 8.0). The genomic DNA was checked on $0.8 \%$ agarose gel and stored at $-20^{\circ} \mathrm{C}$ for further use.

\section{PCR amplification}

Furthermore, to confirm the exact identity of the pathogen, total genomic DNA was used for PCR amplification by primers ITS1 (5'TCCGTAGGTGAACCTGCGG-3') and ITS4 (5'-TCCTCCGCTTA TTGATATGC-3') (White et al., 1990). The DNA amplification was run with 35 cycles with denaturation for $1 \mathrm{~min}$ at $94^{\circ} \mathrm{C}$, primer annealing for 45 seconds at $55^{\circ} \mathrm{C}$, and primer extension for 90 seconds at $72^{\circ} \mathrm{C}$, with an initial denaturation for $3 \mathrm{~min}$ at $94^{\circ} \mathrm{C}$ and a final extension for 15 $\min$ at $72^{\circ} \mathrm{C}$. The final volume of $25 \mu \mathrm{L}$ PCR mix containing $1.5 \mathrm{U} \mathrm{Taq}$ polymerase, $2 \mu \mathrm{L}$ DNA template, $2 \mathrm{mM}$ dNTPs, $25 \mathrm{mM} \mathrm{MgCl} 2$ and 25 pmole of each primer. Gels were stained with ethidium bromide $(10 \mathrm{mg} / \mathrm{mL})$ and were visualized and documented by Alpha digidoc1000 system (Alpha Innotech Corporation, USA). PCR products were loaded ( $1 \mathrm{~h}$ at 80 volts) in $1.2 \%$ agarose gel in Tris-borate-EDTA buffer, $\mathrm{pH}$ 8.0. The amplified PCR products (550bp) were purified by gel extraction kit (Qiagen) and sequencing was done by Eurofins Genomics India Pvt. Ltd (Karnataka, India).

\section{Sequence analysis}

Sequence similarity searches were performed by comparing sequence to sequences available in the database using BlastN1. The sequences showing highest scores with the present isolates were obtained from database and aligned using SEAVIEW program (Galtier, et al., 1996).

\section{Results and Discussion}

The consignment of wooden logs (Tectona grandis) from Panama and Ghana countries were examined by following plant quarantine procedures. During the inspection whitish mycelia mat type growth of fungus was observed on the bark as well as core part of wooden logs. Beneath this superficial growth of mycelium, patches of light to dark brownish discoloration of wood were observed. Hence the infected parts of wooden $\operatorname{logs}$ as well as mycelial growth were collected for lab analysis. In Laboratory the infected wood samples were subjected to isolation procedure. For isolation Potato Dextrose Agar media was used. After isolation the petriplates were incubated at $25 \pm 2^{\circ} \mathrm{C}$ for 10 days. the wood samples and mycelium were also examined under light microscope for morphological studies. After 10 days of incubation on PDA plates, dense mass of white compact mycelium was observed. The mycelial was scraped and placed on a glass slide containing a drop of sterile water. The specimen was observed at 100X magnification under microscope. In microscopic study there was no sporulation on the PDA media. So, the fungal culture was 
further sub-cultured on different media and observations were recorded after 10 days of incubation at $25 \pm 2^{\circ}$. Though profuse mycelial growth was recorded in all the media, abundant sporulation was recorded in Rye agar media whereas, perfect concentric rings were recorded in Potato Carrot agar sometimes forming cottony pustules 15 days after inoculation. Mycelial growth in culture plates produced conidia moderately in concentric rings. There was no pigment diffusion through agar. It was observed that a faint coconut odour was emitted from the pure culture. Conidial masses were light to yellowish green in colour. Under microscopic conidiophores and conidia were observed. Conidiophores were 2.5-3.5 $\mu \mathrm{m}$ wide and conidia broadly ellipsoidal in shape, smooth, $2.8-3.6 \times 2.6-3.0 \mu \mathrm{m}$ in size (Fig. $1-4$ ).

Fig.1a Fungal growth on timber logs covering entire part the wood inside the container

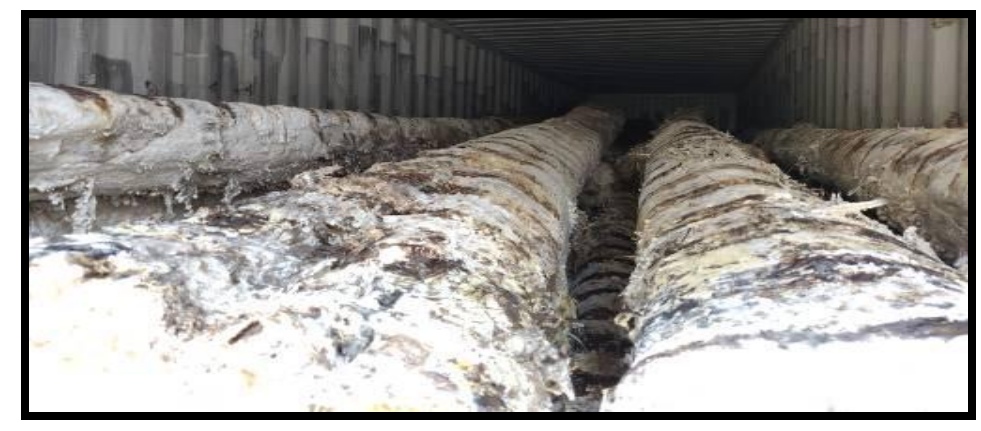

Fig.1b Fungal growth on wooden logs showing discoloration inside the container

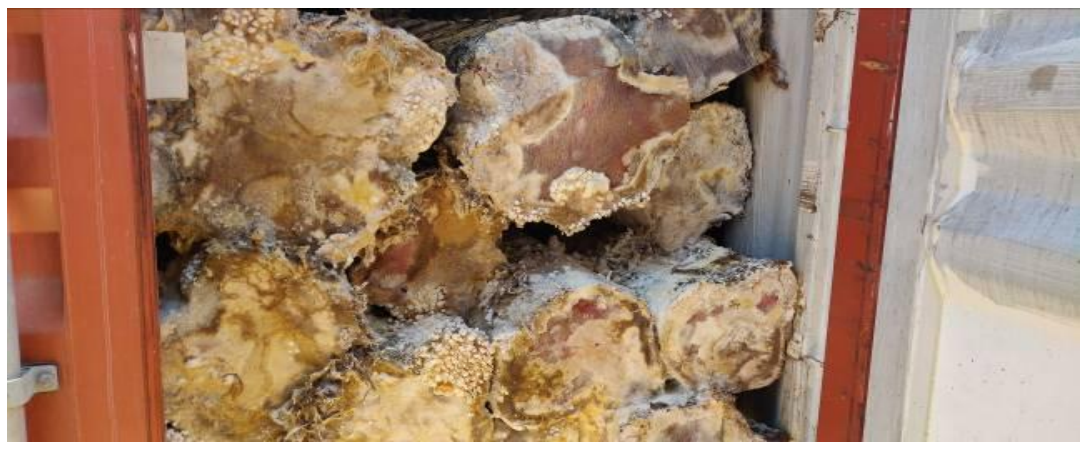

Fig.1c Luxurious fungal growth on timber logs covering core part of the wood logs

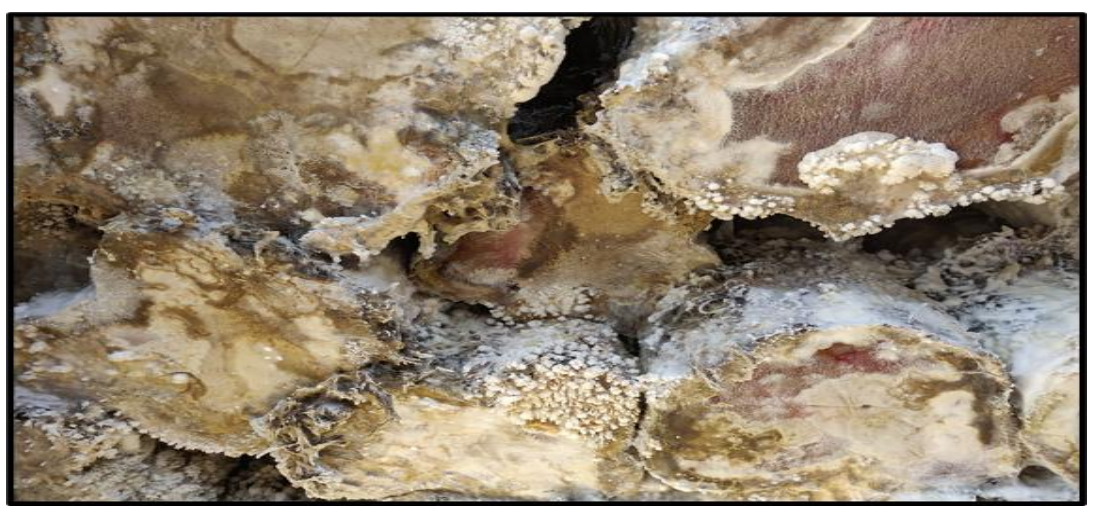


Fig.2 Growth of Trichoderma koningiopsis on different media exhibiting colony characters and sporulation

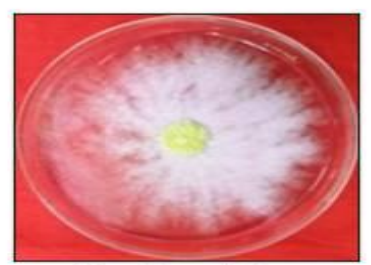

Rose Bengal Agar

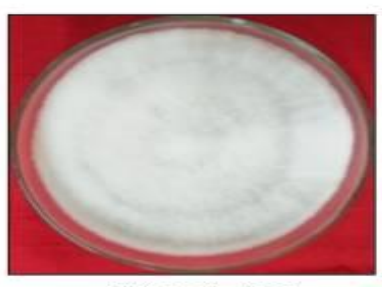

Oat meal Agar

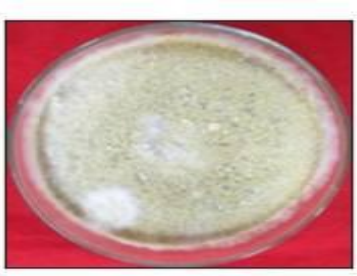

Rye Agar

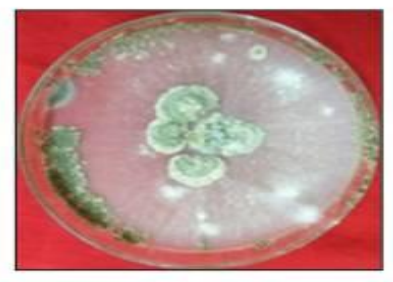

Potato Carrot Agar

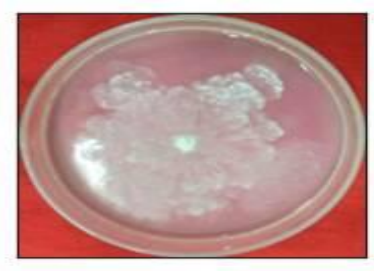

Carrot meal Agar

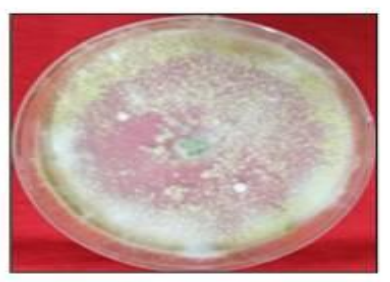

Richard's synthetic Agar

Fig.3 Microscopic view of spores of Trichoderma koningiopsis under $100 \mathrm{X}$ and $40 \mathrm{X}$ magnifications

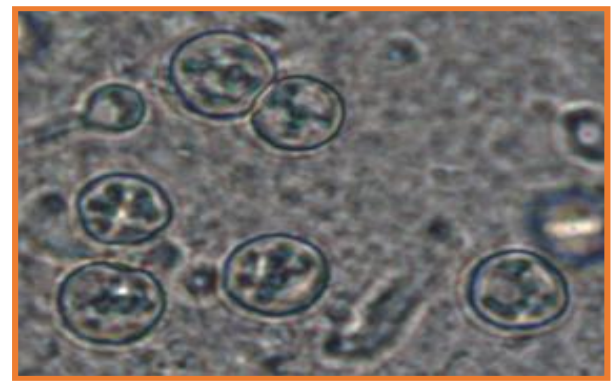

Trichoderma spores (a) $100 \mathrm{X}$

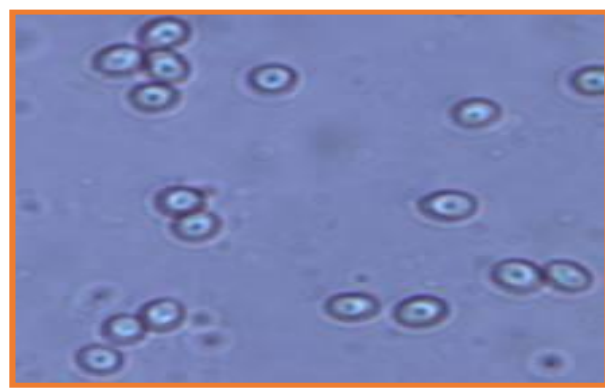

(b) $40 X$

Fig.4 Agarose gel electrophoresis of the PCR products amplified by using ITS 1 and ITS 2 primers

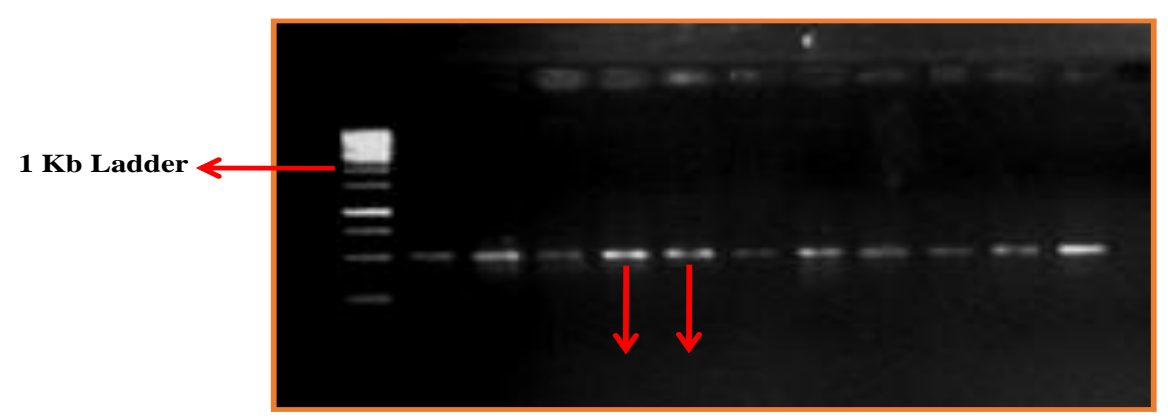

PCR product 1 and 2 
The total genomic DNA was amplified using ITS universal primers. The sequence is available in GenBank (NCBI) with the accession number, KU933355. The ITS sequence of Trichoderma isolate was blasted with other Trichoderma species available in the NCBI database (Hassan, et al., 2019). The blasted results showed $100 \%$ similarity with Trichoderma koningiopsis infecting Lupines albus and Fragaria sp. Therefore, the fungus that caused wood decay and discoloration on Teak wood was identified as Trichoderma koningiopsis based on morphological and Molecular characterization.

As saprotrophs, different species of Trichoderma contribute to the degradation of plant debris, wood and bark (Klein and Eveleigh 1998). Degradation of plant cell wall biopolymers is a complex process, which requires role of a large number of cellulase and hemicellulase enzymes. Several Trichoderma species, has the ability to produce extracellular enzymes i.e. T. harzianum complex, $T$. koningii, $T$. longibrachiatum, $T$. viride, $T$. virens and $T$. citrinoviride (Strakowska et al., 2014). Though several Trichoderma sp. are reported from soil and wood decay T. koningiopsis and T. longibrachatum are preferably isolated from tropical and sub-tropical areas (Kubicek et al., 2008). In a study conducted to identify various woods inhabiting Trichoderma sp. $T$. dorotheae, T. gamsii, and T. koningiopsis were reported for the first time in Korea (Huh et al., 2011). The ability of T. koniniopsis to cause wood decay and wood discoloration was also recorded in a study conducted in Central Europe to identify Trichoderma sp. causing wood decay symptoms in mountain forest of Central Europe (Błaszczyk et al., 2015).

\section{Acknowledgement}

The Plant Protection Advisor, Directorate of Plant Protection Quarantine and Storage,
Faridabad for facilities. The authors are also thankful to ICAR-Indian Institute of Horticultural Research, Division of Plant Pathology, Hessaraghatta, Bangalore, Karnataka, India for their kind support and facilities.

\section{Conflicts of interest}

The authors declare no conflicts of interest.

\section{References}

Doyle JJ, Doyle JL (1990) "Isolation of Plant DNA from Fresh Tissue." Focus 12: 135.

Galtier N, Gouy M, Gautier C (1996) "SEAVIEW and PHYLO WIN: Two Graphic Tools for Sequence Alignment and Molecular Phylogeny." Comput Applic Biosci 12 (6): 543-8.

Hall TA (1999) "BioEdit: A User-Friendly Biological Sequence Alignment Editor and Analysis Program for Windows 95/98/NT." Nucl Acids 41: 95-8.

Hassan M M, Farid MA Gaber A (2019) Rapid identification of Trichoderma koningiopsis and Trichoderma longibrachiatum using sequence characterized amplified region markers, Egyptian J of Biol Pest Cont 29:13 https://doi.org/10.1186/s41938-0190113-0.

Huh N, Jang Y, Lee J, Kim G-H, Kim J-J (2011) Phylogenetic analysis of major molds inhabiting woods and their discoloration characteristics. Part1. Genus Trichoderma. Holzforschung 65: 257-263. http:/dx.doi.org/10.1515/HF.2011.018

Klein D, Eveleigh DE (1998) Trichoderma and Gliocladium. In: Harman GE, Kubicek CP (eds) Trichoderma and Gliocladium, vol 1. Taylor and Francis, London, 57-69.

Kubicek CP (2013) Systems biological approaches towards understanding 
cellulase production by Trichoderma reesei. J Biotechnol 163: 133-142.

Lidia Błaszczyk L, Strakowska J, Chełkowski J, Gąbka-Buszek A, Kaczmarek J (2015) Trichoderma species occurring on wood with decay symptoms in mountain forests in Central Europe: genetic and enzymatic characterization, J Appl Genetics DOI 10.1007/s13353015-0326-1.

Raju J, Gokulraam M, Mohan SM, Keshavamurthy GM, Nagaraju DK, Geetha S, (2019) Interception of live exotic species Cordylomera spinicornis (Fabricius) (Coleoptera: Cerambycidae) in Tali wood imported from African countries, J. Entomol and Zool Studies 7(4): 432-435.

Rao KS Remadevi OK (2006) Bioinvasion, SPS measures and import of wood and wood products into India, TMS 177, TIFAC (DST).

Strakowska J, Błaszczyk L, Chełkowski J (2014) The significance of cellulolytic enzymes produced by Trichoderma in opportunistic lifestyle of this fungus. J Basic Microbiol 54: S2-S13.

Tamura K, Peterson D, Filipski A, Kumar S (2013) "MEGA6: Molecular Evolutionary Genetics Analysis Version 6.0.” Mol. Biol. Evol. 30 (12): 2725-9.

White TJ, Bruns T, Lee S, Taylor J (1990) Amplification and direct sequencing of fungal ribosomal RNA genes for phylogenetics. In: PCR Protocols: A Guide to Methods and Applications. Eds. Innis, M.A., Gelfand, D.H., Shinsky, J.J., White, T.J. Academic Press, San Diego, A. 315-322.

\section{How to cite this article:}

Raju, J., M. Gokulraam, S. Priti, M. Krishna Reddy and Akhtar, M. S. 2021. Interception and Characterization of Trichoderma koningiopsis Reported in Imported Wooden Logs to India. Int.J.Curr.Microbiol.App.Sci. 10(02): 1369-1375. doi: https://doi.org/10.20546/ijcmas.2021.1002.163 